\title{
Study on Historical Memory Fault and Structural Amnesia of Kan Li Siberia Multiple Transmission from Tsinghua Jane "Qiye"
}

\author{
Zhenming Yang ${ }^{1, \text { a }}$
}

${ }^{1}$ College of Chinese Language and Literature of Northwest Normal University, Qinghai, Xining, 810000

${ }^{\mathrm{a}}$ email

Keywords: Kan Li Siberia, Tsinghua Jane, Cultural Anthropology, History, Memory Faults, Structural Collective Amnesia

\begin{abstract}
Kan Li Siberia," since the Song Dynasty, has become a koan academic history, the traditional research mostly on the "Kan Li person" who is in the discussion, Tsinghua Jane "Qiye" come out, understanding the Qin Dynasty "Siberian Kan spread of Lebanon, "the text provides new evidence. From the description of "Kan Li Siberia," the historical documents (historical documents and unearthed literature) carding comparison difficult to find the Qin Dynasty "Kan Li Siberia" has passed this diversity characteristics, rather than as historical documents presented unity. This transition from diversity to unity with First Emperor "Burning of the Books" and Xiang Yu, "Chu a torch" for the critical point, because of the historical memory of the history of man-made vacuum generated (recording) fault, leading to the beginning of the Han Dynasty "Hebrew Kan Li "pluralism is a collective biography of the structural amnesia, so that by the diversity of the Qin Dynasty pass this final pass of the literature handed down to become unity presented.
\end{abstract}

\section{Introduction}

Tsinghua Jane "Qiye" inception, most of scholars concerned with "Kan Li person" who is the problem, the author of "sage night" for the new card, combing through comparative history of literature "Kan Li Siberia," the (handed down and unearthed literature), describes "Kan Li Siberia" text pluralism in mass flow Qin Dynasty.

Slips "Rong Cheng's" contains: Ever since the rebel nine states, abundance, picks, boat, $\mathrm{Pa}$, in, deer, sage, worship, shall be secret's. King Wen heard it, said; "?? Although the monarch is no way, although Chen dared to do something almost no way the Father, do not dare to do almost what the child emperor and reversible?" By the smell, is under the desk and asked King Wen Xia Yan, said: "nine states who may be its peace?" Lord said:. "may" Ever since King Wen prime end Qianshang row nine states, seven states to clothes, abundance, picks satisfied. King Wen is to play a division of HSBC, ho, and into the three drums, three drums retreat, he said: "? I know do more, a person is no way, it's wrong people," Feng, pick the people heard of it, King Wen is down. This paper describes a simple reason soothe King Wen nine states and processes. On the "Book of Rites Wen Wang Shizi •" nine countries mentioned there are well documented. Mr. Ma Chengyuan on this Kan evaluation is: Kan said Wen Ping nine states, the matter although found in "The Book of Rites • Wen Wang Shizi" name then nine states of the the unheard, Confucian not detail their say, was this party known to be abundant, picks and other countries (Brunei, Wu migration are abundant, both as a pick background). The above activities are complemented precious ancient history of the missing material. At the same time, Mr. Ma Chengyuan also noted that "Society" both "Li" as "Society" in the "Book of mass communications" and "Historical Records • Zhou Ji", which in this old haunt southwest Shanxi Changzhi City. From "Rong Cheng's" "Ever since nine states of the rebel" and "Zuo Zhao Gong four years • and "Historical Records • Chu family," "Dong rebellion" King Wen ordered conquest records cross-checked. Known as King Wen Shang nine states rebel conquest carried out, "Although the king is no way, do not dare to do almost Hill? No way, although the parent, the child almost dare to do something? And what can the anti-emperor?" This text is 
completely overturned the Song Dynasty in their home, "Wen Wangzhi De" as the basis, that the King Wen impossible to make following guilty contrary to the monarch of the ceremony thing, therefore said to Wu Kan Li's assertion. Kan King Wen Wen Wang Li is not only no damage, "D' 'image of the sages, but seemed" Zhou on the growing evil "under the condition, but for the King Wen maintains the so" evil "king of the Shang away conquest, more King Wen D'most holy. Documents unearthed this can be said that since the Song Dynasty, "Wu Kan Li," said a fatal blow. However, Tsinghua Jane "Qiye" set: King Wu eight years, conquest Society, the Great Kan. Also, as for the text is drinking too much room. It chronicles the return after cutting Lida Sheng Wu eight years, holding drink to historical events ceremony, $\mathrm{Wu}$ and the ministers for drinking song in the text Mrs Wong chamber. This historical documents and Slips "Rong Cheng's" record "King Wen Li Kan" not consistent.

Kan unearthed from two years of the term, according to the Slips CAS Shanghai Institute of Nuclear Research of the determination, bamboo slips dating from the late Warring States period (2257 \pm 65 years). Mr. Ma Chengyuan think Shanghai Museum's collection of bamboo but moved to Chu Ying previous aristocratic tomb burial articles. Peking University, Tsinghua Jane by Jane did not word fragments radiocarbon determined by tree ring correction of results for $305 \mathrm{BC} \pm 30$ years. From simple text and text features lacquer painted wooden drum remnants Chu painted art style decoration, combined with the entire batch of bamboo shape, finishing believe Tsinghua Jane should be in the territory of Chu during the Warring States Warring States books. Radiocarbon age from fancy bamboo Slips and measurement time of Tsinghua Jane belong to the late Warring States Chu Jane, roughly dating to around 300 BC, and the Tsinghua Slips and Jane who are finishing affirmed these two simple truth sex. Why Chu bamboo slips unearthed literature in the same period on the "Kan Li Siberia" History records are not the same thing, in Dr. Cui Haiying Tsinghua Jane "Golden Teng", "Society for the night", "Fu of life" and the "Book" were related contents after comparative analysis: in sum, we believe that the first point, Tsinghua Jane is independent of the Confucian "Book" Warring States Chu Chuan Chuan present. This has resulted in "Kan Li Siberia," the spread of pluralism, whereby the same period, the same as the Chu Slips unearthed "Rong Cheng's" Tsinghua Jane "Qiye" on the "Kan Li Siberia" stories are documented why will not the same Ming carry on.

\section{The Historical Memory (Recording) Fault}

So what causes Tsinghua Jane "Qiye" "King Wu Keli" Historical Memory fault text stream and pass structural collective amnesia? From the perspective of cultural anthropology, the formation of such faults and structural amnesia collective historical memory of the reasons is nothing less than the result of objective social reality and collective impact of subjective choice.

From the late Qin unified the Warring States to the Han dynasty, "Kan Li Siberia," the history of the subject of this biography pluralism eventually became the unity of the pass. Looking back at history, we can not ignore, it is undeniable that the late Warring States to the Han Dynasty Qin classics experienced "Burning of the Books" and "Chu a torch" twice catastrophe. For both Holocaust Sima Qian described specific and clear in "Historical Records".

Records of Emperor of the century": a non-official historian Qin Chen Please remember all of the burn. The level of non-official Dr., the world dare Tibetan "poetry", "book", 100 speaker, noted Shou Yi, Wei miscellaneous burn it. Dare even language "poetry", "book" were abandoned city, with old days were family. Officials see those who know do not move with the same crime. Thirty days of the order does not burn, tattoos for the Chengdan. Not by the book of divination trees of medicine. This text on the situation and the circumstances surrounding the Emperor Qin book burning were documented. The first thing to note is: "Non-Qin official historian of note are burning," in addition to other things in mind Qin history books as the first to be burned objects, Sima Qian in the "Historical Records - Chronology of the six countries" in exclaimed: "Qin set proud, burn the world of poetry and literature, princes Records is even worse, has its thorn ridiculed too. "in order to prevent scholars Qin Shi Huang" in old days, "all except historical Qin history as burning object. The catastrophe in the case of the destruction of history books from other books of 
historical circumstances described in considerable Qin, under "Mo • Ming ghost chapter": "I see one hundred States", and cited the "week" in the text of the Spring and Autumn Period, "Yan" Spring and Autumn, "Song" of the Spring and Autumn Period, "Qi" of the Spring and Autumn Period. Mozi by the words "I see one hundred States" found that the number of the Qin Dynasty history books very much, rather than a handful of several Western Han Dynasty seen. "Under Lou Mencius - from": King of the track and put out the "poetry" death, "poetry" death and "Spring" for. Jin "multiply," Chu "stool," Lu "Spring", one also. From the above described two books we can see the Qin Dynasty, every country has its own national historical record of their history books, but from the Ban "Han - History" enumerated in the pre-Qin history books point of view, in addition to spread to the Han Dynasty's "Annals" outside the "Warring States", "Mandarin", "Book" and several Shishu Dian Ji, Jin "multiply," Chu "stool" and other countries outside of Qin history books are destroyed. No wonder Sima Qian "Historical Records • Chronology of the six countries," laments: After Qin burn books, poetry and so complex see who can be the possession of the house wall Zhu $\mathrm{Ru}$. Records countries, each Zang their country, and the history of the country off from it. To Han, the unique "Qin mind." Mr. Liu from Yu in the "Book study to theory": it was the Confucian the gathered "book" and the collection "Poems" prepared for two major reader, together with their two outside the classroom practicum "Manners" and "music", together Confucian teaching four courses. Qin rulers hated, the emperor on special devour "Poetry", "book." Seen since ancient times Emperor "book burning" for Shishu Dian Ji destruction is the consensus. Documents unearthed in recent years, a large number of records in the pre-Qin No Historical Documents Handed down view, Sima Qian lamented not unfounded, but the real situation was feeling.

"Burning of the Books" event allows scholars to remain silent, to save their lives no longer ancient papers, learning to read "Poetry", "book." In the Qin and Han Dynasties, nothing less than the history of succession in books and scholars Bachelor of word of mouth. On Emperor "Burning of the Books" event, if say "book burning" is the bearer of Qin history books of the devastation, the "Kengru" is bound to make the pre-Qin classics lost word of mouth Historical Heritage.

From the "Historical Records" record it shows that the "Burning of the Books" is mainly for non-officer Dr private school, the folk medicine book of divination trees except Tibet, "' Poetry "," book ", 100 Whisperer , noted Shou Yi, Wei miscellaneous burn it. "Visible "book burning" is largely destroyed private collection, Dr. officer of the burning of books is not in the column, since columns are not burning books of Dr. officer, in possession of official school books should be retained, why spread to the Han Dynasty when only "Spring and Autumn "' Mandarin "," Book "," The World "," Warring States "and several historical records of it? What has caused the official books of Dr. "disappeared." Qin officials for possession of Shishu Dian nationality "disappeared" Sima Qian did not make a specific record, but the "Historical Records • Xiang Yu Ji", "Xiang Yu led his troops to the West Tu Xianyang, kill Qin lower infant prince, burning the palace of Qin, March eternal fire." And "Historical Records • emperor of the Millennium" in: "Xiang Yu then west, carcasses burned Xianyang Qin palace, which had all broken," the record, we can Qin official collections gone Glimpse evident. It can be inferred that Xiang Yu's "Chu a torch," so that the emperor "Burning of the Books" in the official Tibet and survived because of Shishu Dian Ji wiped out, and no one survived. As Sima Qian said: "After the Qin burn books, poetry and so complex see who can house wall Zhu Ru possession." Visible Qin Shi Shudian membership pass flow path Sima Qian of the Han Dynasty also corroborated the assertion, left to posterity is only a handful of Tibetan folk Qin few historical records, not unearthed until the underground literature, we can only rely on these few limited history books to learn about the history of the Qin. Can not say the emperor's "Burning of the Books" and Xiang Yu, "Chu a torch," caused a cultural fault between the Qin and Han, more importantly, it causes Shishu Dian Ji heritage fault.

Qin unified policy pursued is "destroy their country, to destroy its history", and for the Warring States Period and the Central Plains wide cultural, national prosperity Chu, in addition to "destroy their country, to destroy its history ", the Qin Chu culture implemented tougher policies destruction, Mr. Zhang Zhengming in the" Chu cultural history ": the Qin Dynasty unified eager seeking of Chu culture of exclusion attitude. Especially in Jiangling area, Qin Chu cultural policy implemented 
devastated. Such extreme destruction of culture, so that the mass flow in Chu "Kan Li Siberia" Multiple transmission this be destroyed and exhausted, but sealed in underground literature have been preserved.

Qin Shihuang "Burning of the Books", Xiang Yu's "Ju Chu a" culture of Chu and Qin harsh violence, resulting in "Kan Li Siberia" Multiple transmission this historical memory fault. This man-made historical vacuum generated by historical memory fault, so the beginning of the Han Dynasty "Kan Li Siberia" multiple spread text is structured collective amnesia.

\section{Structural Amnesia}

I follow in the article "structural amnesia" concept Liu Kai, "Wei Yu real test" will be in this article. It is worth emphasizing in this article "Historical Memory (record) the fault of the text is due to objective reality caused by the" "Qiye" "King Wu Li Kan collective" passive forgotten. Two special historical events leading to the Han Dynasty, scholars can not see a more comprehensive history of previous books, it can not be subjective choice but to rely on to escape the "Burning of the Books" and "Ju Chu a" catastrophe the few surviving historical records to the historical heritage of their predecessors, and as a basis to build from what we see today is history, however, this historical heritage is bound to have its limitations and disadvantages of.

This historical memory limitations and defects, leading to future generations can not fully understand the diversity "Kan Li Siberia," A History of mass flow, and thus the choice of this passive transfer of structural pluralism historical events of this amnesia. From the above discussion we can see "Kan Li Siberia," A History of Qin Dynasty, the late Warring States to be late, there have been "King Wen Li Kan" and "King Wu Li Kan" multi pass this, but because of the emperor's experience "burn books Kengru "and Xiang Yu," Chu a torch "twice catastrophe such basic civil and Shishu Dian Ji gone official Qin possession, leaving only a handful of Zhu Ru few historical records of Tibetan house wall, history of this man-made historical events of this historical memory (records) fault, resulting in generations of historians and scholars can not see the whole picture of the pre-Qin history books, only in accordance with the vacuum generated in the two survived the Holocaust in "Book" and build a "Hebrew Kan Li, "the historical memory, eventually leading to the descendants of" Qiye "'" King Wu Li Kan "Biography of the structural collective amnesia, so that the" Kan Li Siberia, "a history of the Warring States period," King Wen Li Kan "and" King Wu Kan $\mathrm{Li}$ "diversity into a single pass of the final pass of the historical documents presented.

History is often much more complex than we can imagine, as before Sanxingdui unearthed thought Shu in Shang and Zhou dynasties should be barren land, but it is not. In 1986 summer, buried a large number of bronze faces of the people, Yu Zhang, Yu Ge, golden rod, gold masks and other artifacts of the two pits at Sanxingdui unearthed the Chengdu Plain. ------ People are the "surprise", also shows that it does not meet the historical image in people's minds - in this border away from the Central Plains of the Upper Yangtze River, Shang and Zhou dynasties should be a wilderness. Therefore, there Sanxingdui culture, indicating that at least since the Han Shu and China have on these "past" amnesia. Unearthed from the recent literature, the Sanxingdui culture phenomenon is not a case. This is how we look at the literature handed down to give new thinking. Mr. Wang Ming-ko in "China edge - Historical Memory and Ethnic Identity", said: In the historical events described in the literature there are obvious errors or when two kinds of data at odds, our work is not just "wheat from the chaff" In the pursuit of historical facts, more importantly, It is to explore why the ancients have different interpretations of the same event records, which reflect what ethnic, class, gender or age differences in social and Change? Although we can not have an existing historical data on the "Kan Li Siberia," the fact that there is a reason why "King Wen Li Kan" and "King Wu Li Kan" Multi record pass streams of detailed discussion, but it is certain that before the late Warring States period on the land of China, "Kan Li Siberia," the text has been widely pluralistic pass flow.

Conclusion: disputes among the Warring States period the war continued, to Shishu Dian membership retention has been unfavorable, First Emperor "Burning of the Books" and Xiang Yu, "Chu a torch," so many history books record Qin destroyed, eventually leading to the Han "Qiye" 
"King Wu Li Kan" Biography Reuben collective historical memory faults and structural amnesia. The historical memory of the history of man-made vacuum generated (recording) fault, so the beginning of the Han Dynasty "Kan Li Siberia" pluralism is a collective biography of the structural amnesia, so that the transfer of the diversity of the Qin Dynasty eventually became handed down literature presented pass this unity, the "Society for the night", "Wu Kan Li" Biography Reuben was dusty ground, people's memories fade.

\section{References}

[1] Ma Chengyuan. Bamboo Slips Found Protection and Consolidation [J]. Chinese Cultural Relics News, 2001.

[2] Liu Guozhong. Into Tsinghua Jane [M]. Beijing Higher Education Press, 2011.

[3] Si Maqian. Historical Records Chronology of the Six Countries [M]. Beijing, Zhonghua Book Company, 2013.

[4] Ma Chengyuan. Bamboo Slips Found Protection and Consolidation [J]. Chinese Cultural Relics News, 2001.

[5] Tsinghua Unearthed Literature Research and Conservation Center Compiled, Edited By Li Xueqin, Tsinghua Tibetan Warring States Bamboo [M]. Shanghai: Western Publishing House, 2011.

[6] Ma Chengyuan. Shanghai Museum Bamboo Slips [M]. Shanghai: Shanghai Ancient Books Publishing House, 2002.

[7] Liu Guozhong. Into Tsinghua Jane [M]. Beijing Higher Education Press, 2011.

[8] Cui Haiying. Hole Transfer "Ancient Book" Sources of the Problem with A Book In 2014.

[9] Sima Qian, Records of Emperor of the Century [M]. Beijing, Zhonghua Book Company, 2013.

[10] Mencius, Mencius Ivb [M]. Beijing, Zhonghua Book Company, 2013.

[11] Zhang Zhengming. Chu Cultural History [M]. Taipei, South Bookstore Distribution, 1987.

[12] Wang Mingke. Heroes and Ancestors Ethnic Brethren the Foundation of the History of the Text and Context [M]. Beijing, Zhonghua Book Company, 2012.

[13] Wang Mingke. China Edge-Historical Memory and Ethnic Identity [M]. Hangzhou, Zhejiang People's Publishing House, 2013. 